\title{
Social, economic, and behavioral variables associated with oral health-related quality of life among Brazilian adults
}

\author{
Variáveis sociais, econômicas e comportamentais associadas à saúde \\ bucal relacionada à qualidade de vida em adultos brasileiros
}

Marilisa Carneiro Leão Gabardo ${ }^{1}$

Samuel Jorge Moysés ${ }^{1}$

Simone Tetu Moysés ${ }^{1}$

Marcia Olandoski ${ }^{1}$

Maria Teresa Anselmo Olinto ${ }^{2}$

Marcos Pascoal Pattussi ${ }^{2}$

Escola de Saúde e Biociências, Pontifícia Universidade Católica do Paraná. R. Imaculada Conceição 1155, Prado Velho. 80215-901 Curitiba PR Brasil. marilisagabardo@ e-odonto.com ${ }^{2}$ Programa de PósGraduação em Saúde, Centro de Ciências da Saúde, Universidade do Vale do Rio dos Sinos.
Abstract The aim of this study was to investigate the association between sociodemographic, socioeconomic, psychosocial, and behavioral variables and oral health as assessed using the 14-question short version of the Oral Health Impact Profile (OHIP-14). A cross-sectional study was performed with 1095 adult residents from 38 census tracts in the municipality of São Leopoldo, State of Rio Grande do Sul, Brazil. Responses to the OHIP-14 were dichotomized, and bivariate (Chi-square) and multivariate analysis (logistic regression and Wald's test) were performed. In the bivariate analysis, the worse effects were reported by female individuals, the elderly, those with low family income, less schooling, those reporting a lower quality of life and social support, and smokers. In the multivariate analysis the following variables maintained their statistical significance: gender (female), age (50-59 years), family income (low), quality of life (low), social support (low, moderate), and smoking (smokers). Individuals self-perception of their oral health was related to sociodemographic, socioeconomic, psychosocial, and behavioral variables, thus confirming that emphasis should be placed on social factors when addressing oral health problems.

Key words Epidemiology, Quality of life, Oral health
Resumo O objetivo deste estudo foi investigar a associação entre as variáveis sociodemográficas, socioeconômicas, psicossociais e comportamentais e a saúde bucal por meio da versão abreviada do Perfil de Impacto em Saúde Oral, Oral Health Impact Profile (OHIP-14). Estudo transversal que contou com 1095 adultos residentes nos 38 setores censitários do município de São Leopoldo $R S$, Brasil. As respostas ao OHIP-14 foram dicotomizadas e a análise bivariada (Qui-quadrado)e multivariada (regressão logística e teste de Wald) foram realizadas. $\mathrm{Na}$ análise bivariada, os piores efeitos foram relatados por mulheres, individuos com idade mais avançada, com baixa renda familiar e menor escolaridade, por aqueles com relato de menor qualidade de vida e apoio social e por fumantes. Na análise multivariada as seguintes variáveis mantiveram significância estatística: gênero (mulheres), idade (50-59 anos), renda familiar (baixa), qualidade de vida (baixa), apoio social (baixo e moderado) e hábito de fumar (fumantes). A autopercepção individual da saúde bucal foi relacionada às variáveis pesquisadas, confirmando que deve ser dada ênfase aos fatores sociais ao se tratar de problemas de saúde bucal. Palavras-chave Epidemiologia, Qualidade de vida, Saúde bucal 


\section{Introduction}

Clinical and epidemiological measurements, such as indices of dental caries and periodontal disease, are traditionally used to analyze oral health condition sat both the individual and population level ${ }^{1}$. This approach is based on the dichotomous determination of either the presence or absence of disease, in which only the professional makes the diagnostic and therapeutic decisions. This biomedical model is still commonly used by dental professionals ${ }^{2}$. However, a transition away from this practice of unilateral oral health evaluation has prompted discussion about the issue of oral health concerns that are more associated with sociodemographic, socioeconomic, psychosocial, and behavioral variables, and which can better incorporate individuals' subjective and self-perceived factors ${ }^{3,4}$.

In addition, the literature has increasingly provided evidence that increased rates of oral diseases and disorders are related to higher levels of social inequities, thereby demonstrating the deleterious effect social factors can have on health ${ }^{5-8}$. While the findings of these previous studies are revealing, they also bring up new hypotheses that seek to establish how subjective factors and quality of life are associated with both the general and oral health condition of individuals and populations ${ }^{9}$.

In the case of general health, self-rated health appears to be affected by sociodemographic factors and the environmental conditions in which individuals live ${ }^{10}$. In the case of oral health, it is important to understand the associations between oral health disorders and people's performance of daily activities, including the possible impact this has on their quality of life. Clinical measures of oral health, perceptions of oral and general health conditions, as well as reported physical, social, and psychological functions, are regarded as independent but potentially correlated variables that together comprise the oral health-related quality of life (OHRQoL) ${ }^{11}$. Key concerns are related to subjective experiences, such as self-image, comprehension of personal needs, and the seeking of oral care ${ }^{12}$. The way in which individuals perceive their oral condition appears to be linked to a series of factors relating to social inequities, such as social class, schooling, and income $\mathrm{e}^{13-15}$.

The so-called socio-dental indicators were designed to analyze the impact of oral health problems on individuals' quality of life ${ }^{16}$. Examples of these indicators include the Geriatric Oral
Health Assessment Index (GOHAI) ${ }^{17}$, Dental Impact on Daily Living (DIDL) ${ }^{18}$, Oral Impacts on Daily Performances (OIDP) ${ }^{19}$, the Oral Health Impact Profile (OHIP) ${ }^{3}$, and its short version, the OHIP- $14^{20}$.

The OHIP-14 is preferred among these indicators because it can be easily applied ${ }^{20}$. This indicator has been used in diverse locations, and adaptations have been made to take into account cultural differences among population groups regarding perceptions of health ${ }^{21-23}$. This has been used in studies involving age groups ranging from children ${ }^{24}$ to the elderly ${ }^{25}$. It has also been used to research the impact of other variables on oral health, including gender ${ }^{26-29}$, schooling ${ }^{15,26-30}$, age $\mathrm{e}^{15,26,28-30}$, and income $\mathrm{e}^{15,27-29,31}$, as well as behavioral factors such as smoking ${ }^{15,27,30}$, the consumption of alcohol and other drugs ${ }^{15,30}$, and oral hygiene habits ${ }^{32}$.

In Brazil, the OHIP-14 has undergone trans-cultural validation ${ }^{33}$, and its psychometric capacity has also been evaluated ${ }^{24,34}$.

Based on the assumption that many variables can influence subjective oral health (which affects quality of life), and given that exploration of this field is still needed, this study aimed to investigate the association between OHIP-14 and sociodemographic, socioeconomic, psychosocial, and behavioral variables in adults in the municipality of São Leopoldo, state of Rio Grande do Sul (RS), Brazil.

\section{Methods}

This cross-sectional, quantitative, populationbased study included a random sample of 1095 subjects aged 18 years and older in the municipality of São Leopoldo, RS, Brazil. Its location is in the Rio dos Sinos Valley, a metropolitan area of the state capital, Porto Alegre. In 2000, the reference year for demographic data used in this study, the city's population was 194,000. The city's public service network includes one general hospital and 28 primary health care units.

The sample size used in this study was calculated based on a pilot study and statistical procedures. The number of households in the sample size was increased by $20 \%$ to compensate for losses due to follow-up and to control for confounders. A total of 1,512 households that were distributed among 40 census tracts (randomly chosen) were selected. Blocks within the census tracts were also randomly selected, and 
all households within a block were visited until the target number of 38 participating households was reached. If the resident was not present at the time of the visit, the interviewers would return up to three times for data collection ${ }^{10}$.

A structured, standardized, previously tested questionnaire was administered to obtain data for this study ${ }^{10}$.The outcome variable of interest was the OHIP-14, which was obtained using questions from a measure that had previously been validated for use in Brazil ${ }^{33}$. This short version of the questionnaire consisted of the same seven dimensions that are used in the original OHIP-49: functional limitation, physical pain, psychological discomfort, physical disability, psychological disability, social disability, and handicap ${ }^{20}$. The OHIP-49 provides a self-reported measure of oral health ${ }^{20}$ and is based on Locker's theoretical model of oral health ${ }^{35}$, capturing the various influences of oral health in a hierarchical order.

To obtain this outcome variable, the following guiding question was used in the questionnaire: "How frequently has the following happened to you in the last six months because of problems with your teeth, mouth, or denture?" For example, "How frequently have you had difficulty pronouncing any word in the last six months because of problems with your teeth, mouth, or denture?" Possible responses were never, hardly ever, occasionally, often, and very often. Corresponding values were given to the above answers, ranging from 0 to 4 .

The outcome variable was dichotomized, such that the individuals who answered "often" or "very often" at least once were classified into OHIP-1 (bad oral health condition), while the remaining individuals (who answered "never", "hardly ever", and "occasionally") were classified into OHIP-0 (good oral health condition). This classification enabled the quantitative depiction of functional and psychosocial impacts relating to poor oral health that were experienced during a set time period ${ }^{36,37}$.

The independent variables were also collected using the same questionnaire. Sociodemographic variables included gender (male/female), observed skin color (white/non-white), and age (stratified into10-year intervals). The socioeconomic variables were family income (in Real, the Brazilian currency) and schooling (years of study). These variables were categorized in quartiles as follows: high (top 25\% of scores), moderate (middle 50\%), and low (bottom 25\%). The same means of categorization were adopted for the psychosocial variables (i.e., quality of life and social support), based on participants' scores.

The data on quality of life were obtained by asking questions relating to personal satisfaction with health, relationships, and housing, among other variables ${ }^{38}$. Answers varied from "very satisfied" to "very unsatisfied" on a five-point scale ranging from 0 to 4 . Total minimum and maximum possible scores were 0 and 32 , respectively, with higher scores indicating higher quality of life. Data on social support were obtained by following the methodology proposed by the Medical Outcomes Study (MOS) ${ }^{39}$ and were collected using a 19-item questionnaire regarding materialism, affective and emotional dimensions, positive social interaction, and information. Item scores ranged from 0 to 4 , and the total possible scores were between 0 and 76. Again, higher scores signified a higher level of reported social support.

The behavioral variable of eating habits (e.g., consumption of fruits and vegetables) was categorized as follows: low consumption $=$ no servings of fruits or vegetables; moderate consumption $=1-2$ fruits/day and 1-4 servings of vegetables/day; high consumption $=\geq 3$ fruits/day and $\geq 5$ servings of vegetables/day. Information on smoking status (nonsmoker, former smoker, and smoker) and alcohol intake (none/moderate < $8 \mathrm{mg}+9$ and $<15 \mathrm{mg} \delta /$ day; yes/excessive $\geq 8 \mathrm{mg}$ $\rightarrow$ and $\geq 15 \mathrm{mg} \hat{\delta} /$ day) were also collected ${ }^{40}$.

In the bivariate analysis, the Chi-square test with significance set at $\mathrm{P}<.05$ was used to identify significant associations between the explanatory variables and their ability to predict the outcome of interest, namely OHIP-14. Finally, to perform a joint evaluation of the oral health related variables that were considered in the study, the logistic regression model was used. Because the design effect for OHIP was 2.29 and because de cluster sample, sampling weights and control for complex sampling were used. Multivariable models included only variables with $\mathrm{P}<.20$ in the bivariable analysis. Wald's test was also used to evaluate the importance of each variable in the presence of the other variables. Values of $\mathrm{P}<.05$ and their respective confidence intervals indicated statistical significance.

The analysis was performed using Stata version 12 (StataCorp, College Station, Texas, USA). This study was approved by the Vale do Rio dos Sinos University - UNISINOS Research Ethics Committee. 


\section{Results}

Among the 38 census tracts in São Leopoldo, interviews were conducted in 1,100 households. After exclusion of missing data, a final sample of 1,095 subjects was analyzed. In this, $71.8 \%$ of participants were females, while white respondents accounted for $83.8 \%$ of the sample. The average age was 44.2 years $(S D=15.8)$, with the minimum age being 18 years and the maximum age being 90 years. The average number of years of schooling was 8.2 years $(\mathrm{SD}=4.1)$. The prevalence of the worst outcome, OHIP-1, was $15.9 \%$, with a frequency of 174 cases. The results of distribution, prevalence, and unadjusted and adjusted odds ratios are presented in Table 1.

A significant difference was found between men and women in terms of oral health, using both bivariate $(\mathrm{P}<.001)$ and multivariate analyses $(\mathrm{P}=.001)$. In the latter analysis, being female increased the chances of self-reporting poor oral health by almost 2.6 times [OR 2.63 (CI 95\%: $1.50-4.59)]$.

After multivariate analysis, the age 50-59 years was the only category that maintained statistical significance $(\mathrm{P}=.004)$.

No significant differences were found in either type of analysis with respect to skin color ( $\mathrm{P}$ $=.498)$.

With respect to family income and schooling, significant differences arose in OHIP-14 scores with bivariate analysis, with $\mathrm{P}$ values of .042 and .002 , respectively. However, this significance did not survive multivariate analysis.

Regarding the psychosocial variables, the lowest scores were associated with a higher probability of reporting poor oral health. For example, low quality of life increased the probability of self-reporting poor oral health by approximately four times [OR 3.78 (95\% CI: 1.86-7.66)]. Also, low and moderate social support showed the same behavior [OR 1.80 (95\% CI: 1.17-2.78); OR 2.05 (95\% CI: 1.22-3.46)].

With respect to the behavioral variables, eating habits $(\mathrm{P}=.344)$ and alcohol intake $(\mathrm{P}=$ .856) were not significantly related to oral health outcome. This result was contrary to that of smoking, which (smoker) maintained its significance in both bivariate and multivariate analyses; thus, in the logistic regression, smokers reported a higher impact on oral health scores [OR 2.73 (95\% CI: 1.59-4.71)].

\section{Discussion}

This study investigated the association between individual and contextual variables and the self-perception of oral health quality of life in adults.

There are critical considerations that should be made regarding the methodological choices that were used in this study. The instrument that was chosen as the dependent variable, OHIP-14, was found to be useful for the measurement of oral health-related quality of life. These findings confirm its value in international surveys, which is supported by earlier studies that have used this measure $^{26,27,29,31}$. In Brazil, recent investigations have also used the OHIP- $14^{15,29}$ and have confirmed its psychometric capabilities ${ }^{24,34}$. Although this instrument is a short version of the original 49-item questionnaire, the aims of OHIP-14 are the same, with the added advantage of reduced application time ${ }^{20}$.

Responses to the OHIP-14 were dichotomized in order to identify the prevalence of negative impacts more clearly, i.e., the percentage of individuals who answered "often" and "very often." This strategy has been employed previously in other studies with the OHIP-14 $4^{36,37}$. Similar rates of the worst outcome, OHIP-1, have also been found in prior investigations, with values ranging from $16.2 \%$ to $19.5 \%{ }^{25,31}$.

The percentage of women who reported poorer oral health self-perceptions in the current study was similar to rates reported in previous studies $^{26,29,31,32}$. This may reflect the higher participation of females in the samples that were examined; however, the significance of these findings has not yet been discussed in the literature ${ }^{12}$. It is important to emphasize that the interviews were conducted during working hours, which could explain the high number of female respondents, a typical situation found in Brazilian domiciliary studies. Consequently, as reported in a previous study that used the same database, these women are possibly more influenced by their poor surroundings, as they spend most of their time in these neighborhoods, potentially suffering from a lack of public services and amenities ${ }^{10}$. These gender differences are particularly significant, considering women tend to take better care of their health and seek health services when needed. Thus, there is a greater impact on them when no public services are available $e^{41,42}$.

In the current study, individuals aged 40 and over perceived a greater impact of oral health on their quality of life. Old age and less education 
Table 1. Distribution, prevalence, and odds ratio (OR) of OHIP-14 according to the individual explanatory variables in adults from the municipality of São Leopoldo, RS, Brazil, 2007 ( $n=1,095)$.

\begin{tabular}{|c|c|c|c|c|c|c|c|}
\hline Variable & $\mathbf{n}$ & $\begin{array}{l}\text { OHIP-0 } \\
\text { n (\%) }\end{array}$ & $\begin{array}{l}\text { OHIP-1 } \\
\text { n (\%) }\end{array}$ & $\begin{array}{c}\mathrm{P}^{\mathrm{a}} \\
\text { value }\end{array}$ & $\begin{array}{c}\text { Non-adjusted } \\
\text { OR } \\
(95 \% \mathrm{CI})\end{array}$ & $\begin{array}{c}\mathrm{P}^{\mathrm{b}} \\
\text { value }\end{array}$ & $\begin{array}{l}\text { Adjusted } \\
\text { OR } \\
(95 \% \mathrm{CI})\end{array}$ \\
\hline \multicolumn{8}{|l|}{ Gender } \\
\hline Male & 309 & $283(91.6)$ & $26(8.4)$ & & 1 & & 1 \\
\hline Female & 786 & $638(81.2)$ & $148(18.8)$ & $<.001$ & $\begin{array}{c}2.52 \\
(1.63-3.92)\end{array}$ & .001 & $\begin{array}{c}2.63 \\
(1.50-4.59)\end{array}$ \\
\hline \multicolumn{8}{|l|}{ Skin color } \\
\hline White & 910 & $776(84.4)$ & $143(15.6)$ & & 1 & & \\
\hline Non-white & 174 & $143(82.2)$ & $31(17.8)$ & .498 & $\begin{array}{c}1.18 \\
(0.77-1.80)\end{array}$ & & \\
\hline \multicolumn{8}{|l|}{ Age (years) } \\
\hline $18-29$ & 247 & 227 (91.9) & $20(8.1)$ & & 1 & & 1 \\
\hline $30-39$ & 181 & $158(87.3)$ & $23(12.7)$ & & $\begin{array}{c}1.65 \\
(0.88-3.11)\end{array}$ & .776 & $\begin{array}{c}1.09 \\
(0.57-2.06)\end{array}$ \\
\hline $40-49$ & 257 & $211(82.1)$ & $46(17.9)$ & $<.001$ & $\begin{array}{c}2.47 \\
(1.42-4.32)\end{array}$ & .085 & $\begin{array}{c}1.89 \\
(0.91-3.92)\end{array}$ \\
\hline $50-59$ & 217 & $169(77.9)$ & $48(22.1)$ & & $\begin{array}{c}3.22 \\
(1.84-5.63)\end{array}$ & .004 & $\begin{array}{c}2.46 \\
(1.36-4.47)\end{array}$ \\
\hline$\geq 60$ & 193 & $156(80.8)$ & $37(19.2)$ & & $\begin{array}{c}2.69 \\
(1.50-4.81)\end{array}$ & .110 & $\begin{array}{c}2.01 \\
(0.84-4.77)\end{array}$ \\
\hline \multicolumn{8}{|l|}{ Family income $(\mathrm{R} \$)^{c}$} \\
\hline High $(\geq 3185)$ & 282 & $246(87.2)$ & $36(12.8)$ & & 1 & & \\
\hline $\begin{array}{l}\text { Moderate } \\
(1049.01-3184.99)\end{array}$ & 588 & $497(84.5)$ & $91(15.5)$ & .042 & $\begin{array}{c}1.25 \\
(0.83-1.89)\end{array}$ & .992 & $\begin{array}{c}1.00 \\
(0.54-1.83)\end{array}$ \\
\hline Low $(\leq 1049)$ & 225 & $178(79.1)$ & $47(20.9)$ & & $\begin{array}{c}1.80 \\
(1.12-2.90)\end{array}$ & .974 & $\begin{array}{c}.989 \\
(0.52-1.86)\end{array}$ \\
\hline \multicolumn{8}{|l|}{ Schooling (years) } \\
\hline $\operatorname{High}(\geq 12)$ & 166 & $150(90.4)$ & $16(9.6)$ & & 1 & & 1 \\
\hline Moderate (5-11) & 695 & $590(84.9)$ & $105(15.1)$ & .002 & $\begin{array}{c}1.67 \\
(0.96-2.90)\end{array}$ & .922 & $\begin{array}{c}1.04 \\
(0.46-2.33)\end{array}$ \\
\hline Low $(\leq 4)$ & 204 & $158(77.5)$ & $46(22.5)$ & & $\begin{array}{c}2.73 \\
(1.48-5.03)\end{array}$ & .682 & $\begin{array}{c}1.21 \\
(0.47-3.12)\end{array}$ \\
\hline \multicolumn{8}{|l|}{ Quality of life } \\
\hline High $(\geq 30)$ & 238 & $217(91.2)$ & $21(8.8)$ & & 1 & & 1 \\
\hline Moderate (27-32) & 625 & $547(87.5)$ & $78(12.5)$ & $<.001$ & $\begin{array}{c}1.47 \\
(0.89-2.44)\end{array}$ & .561 & $\begin{array}{c}1.17 \\
(0.67-2.05)\end{array}$ \\
\hline Low $(\leq 26)$ & 232 & $157(67.7)$ & $75(32.3)$ & & $\begin{array}{c}4.94 \\
(2.92-8.35)\end{array}$ & $<.001$ & $\begin{array}{c}3.78 \\
(1.86-7.66)\end{array}$ \\
\hline \multicolumn{8}{|l|}{ Social support } \\
\hline High $(\geq 95)$ & 380 & $338(88.9)$ & $42(11.1)$ & & 1 & & 1 \\
\hline Moderate (75-94) & 436 & $363(83.3)$ & $73(16.7)$ & .001 & $\begin{array}{c}1.62 \\
(1.08-2.43)\end{array}$ & .008 & $\begin{array}{c}1.80 \\
(1.17-2.78)\end{array}$ \\
\hline Low $(\leq 74)$ & 276 & 217 (78.6) & $59(21.4)$ & & $\begin{array}{c}2.19 \\
(1.42-3.37)\end{array}$ & .008 & $\begin{array}{c}2.05 \\
(1.22-3.46)\end{array}$ \\
\hline
\end{tabular}

it continues

are factors commonly associated with psychosocial problems related to poor oral health ${ }^{26,29,43}$. However, other studies have shown no association between these variables and OHIP-14, or significance has been lost when using multivar- 


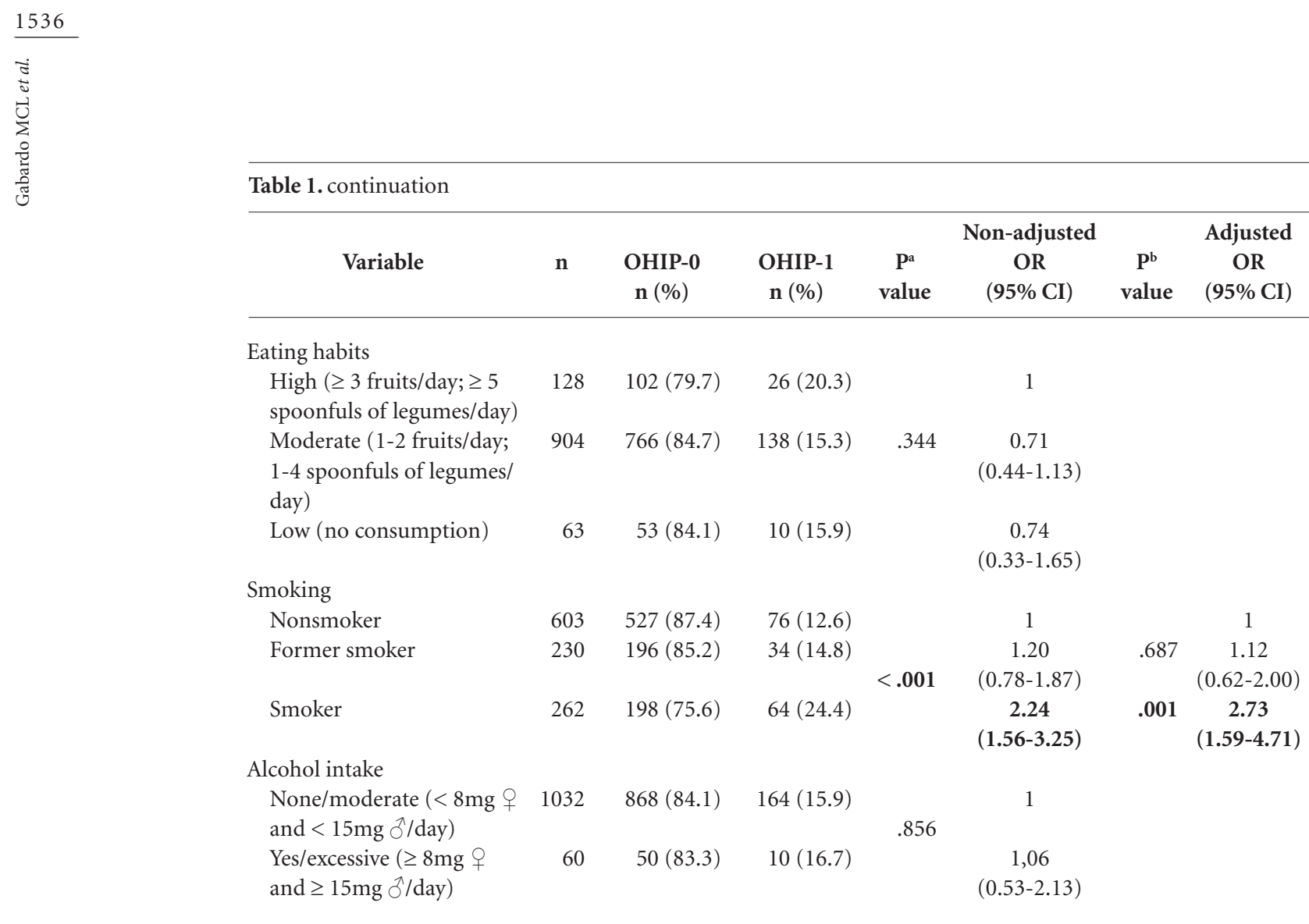

Bold values are statistically significant, $\mathrm{P}<.05 .{ }^{\mathrm{a}}$ Chi-square test. ${ }^{\mathrm{b}}$ Logistic Regression and Wald's Test. ${ }^{\mathrm{c}}$ USD $1=\mathrm{R} \$ 2$ (in 2006 ).

health ${ }^{15,31,44}$. However, in the current study, income lost explanatory power in the multivariate analysis; this may be because other variables were stronger determinants of oral health self-perception.

The lack of significance between skin color and oral health was in accordance with the findings of previous studies ${ }^{43}$. However, there are some examples in the literature of nonwhites reporting oral symptoms more often than whites ${ }^{15,44}$

Regarding the psychosocial variables, this study showed a clear relationship between better living conditions and a more favorable perception of oral health, as has been observed in previous studies ${ }^{11}$.

The perception of quality of life is largely subjective, and the manner in which individuals perceive their quality of life can vary according to their social, cultural, and political conditions ${ }^{45}$. As such, the debate on this issue may be inconclusive, as these results are an estimation of accounts that are permeated by a multidimensional complexity ${ }^{46}$.

It must also be taken into consideration that the attitudes of the individuals are not constant, and they can change over time and according to their experiences. A problem that was considered to be important at one given time point may become relatively unimportant at another. This phenomenon is referred to as "dynamic construct" 47 . Taking into account these possible individual variations in responses, the variables related to quality of life are interpreted with caution.

With respect to social support, Berkman et $\mathrm{al}^{48}$ discuss the impact of social network on people's social and interpersonal behavior. The relationships people develop in their early life may result in positive or negative behaviors that can affect the presence or absence of diseases as adults. Macro-factors - such as socio-structural conditions - influence social network, which influences the psychosocial mechanisms that affect people's choices and lifestyles, such as smoking, alcohol intake, physical exercise, psychological alterations, and changes to the body in general. This finding appears to be in agreement with the results of this study, as low social support and smoking increased the likelihood of bad oral health self-perception. Other findings confirm this result, showing that harmful behavioral habits were associated with worse OHRQoL ${ }^{30}$. Oral hygiene habits also follow this pattern ${ }^{32}$, and in a study of European workers from 28 countries, social support and social exclusion helped to ex- 
plain the social differences in men and women's self-perception of health ${ }^{49}$.

On this same topic, a prospective study with 1,043 pregnant and post-partum women conducted by Lamarca et al. ${ }^{15}$ demonstrated that women with an external work-based network have more social support and show better OHIP14 scores than those with a home-based network who have no income or are unemployed.

A number of social conditions are associated with self-perception of the impact of oral health on quality of life. These are described in a review of 40 publications, which indicates the important role of social determinants as impact modulators and as having an effect on the quality of life. The results indicate that a negative impression is more frequently experienced by women, individuals with low education and income, and by immigrants or people belonging to minority ethnic groups ${ }^{14}$. Results from the literature strengthen the hypothesis that both individual determinants and contextual determinants are capable of influencing the manner in which the subjects perceive themselves in terms of general health ${ }^{10}$ and oral health ${ }^{15,26-32}$.

It is important to highlight that greater exposure to risk factors, such as material deprivation, unemployment, discrimination, problems with transportation or housing, and poor access to resources and services, results in the social production of diseases and disorders ${ }^{50-52}$. In these conditions, the emergence of health inequities is almost unavoidable.

These findings suggest the need for further studies, including longitudinal research, to elucidate the associations that were found in this study. The current study design has some limitations, and therefore only the examination of associations could be performed at present. An assessment of variability along a time scale may reveal oral health conditions that were once considered bad, but are now perceived positively by the individual. For example, wearing dentures at present would be considered good, meaning the predating toothache, tooth loss, and oral rehabilitation with the prosthesis may have actually led to a stronger self-perception. However, the situation may still be more complex. For example, a previous cohort study about self-perception of health indicated that after five years, $47.4 \%$ of those who were interviewed a second time did not report any alterations in their health, despite the occurrence of many significant changes ${ }^{53}$.

Another limitation of this study is the lack of aggregation of clinical variables in the analysis. This may be directly associated with the variation in the perception of impacts and, consequently, in quality of life, independent of sociodemographic and socioeconomic factors ${ }^{29}$. It is recognized that the generic measures of health are not sensitive to oral health outcomes. Disease-specific measures are more likely to detect the subtle changes in specific conditions, and thus show better responsiveness. It is ideal, then, to use evaluations in which both types of measurements are applied ${ }^{4}$. Considering that general oral diseases usually develop slowly, there are some time-related difficulties in reaching a more precise convergence between a poor clinical condition and the patient's negative self-perception, except in the case of a specific problem, such as toothache.

Subjective health evaluations can be applied in policy, theory, and practice as follows: in policy, increasing the awareness of public policy-makers and decision-makers of these types of evaluations, so that they can integrate these issues into existing strategies focused on healthy living; in theory, by including them in the agenda of health service studies as well as medical, sociology, and psychology discussions and research; and in practice, by incorporating them in research focusing on public health, as well as using them in clinical practice ${ }^{2}$.

\section{Conclusions}

The OHIP-14 is a subjective and relevant instrument that enables people to self-report the impact of oral health on quality of life. Diverse variables and factors that were included in this study appear to influence this perception in a favorable or unfavorable manner. Being female, being older in age, having lower family income and less schooling, having a low quality of life and low social support, and smoking were all associated with higher rates of bad oral health impact. These results can support clinical findings and also help in designing more specific strategies to reduce oral health problems. 


\section{Collaborations}

MCLG prepared the article and performed the data analysis; SJM oversaw the data analysis and the final version of the article; STM contributed to writing the article; $\mathrm{MO}$ assisted in data analysis; MTAO assisted in data analysis; MPP gave final approval of the version to be published.

\section{References}

1. World Health Organization (WHO). Oral health surveys: basic methods. Geneva: WHO; 1997.

2. Locker D. Applications of self-reported assessments of oral health outcomes. J Dent Educ 1996; 60(6):494-500.

3. Slade GD, Spencer AJ. Development and evaluation of the Oral Health Impact Profile. Community Dent Health 1994; 11(1):3-11.

4. Allen PF. Assessment of oral health related quality of life. Health Qual Life Outcomes 2003; 1:40.

5. Pattussi MP, Marcenes W, Croucher R, Sheiham A. Social deprivation, income inequality, social cohesion and dental caries in Brazilian school children. Soc Sci Med 2001; 53(7):915-925.

6. Antunes JLF, Peres MA, de Campos Mello TR, Waldman EA. Multilevel assessment of determinants of dental caries experience in Brazil. Community Dent Oral Epidemiol 2006; 34(2):146-152.

7. Bastos JL, Boing AF, Peres KG, Antunes JL, Peres MA. Periodontal outcomes and social, racial and gender inequalities in Brazil: a systematic review of the literature between 1999 and 2008. Cad Saude Publica 2011; 27(Supl. 2):141-153.

8. Sheiham A, Alexander D, Cohen L, Marinho V, Moysés S, Petersen PE, Spencer J, Watt RG, Weyant R. Global oral health inequalities: task group-implementation and delivery of oral health strategies. Adv Dent Res 2011; 23(2):259-267.

9. Locker D, Gibson B. Discrepancies between selfratings of and satisfaction with oral health in two older adult populations. Community Dent Oral Epidemiol 2005; 33(4):280-288.

10. Cremonese C, Backes V, Olinto MTA, Dias-da-Costa JS, Pattussi MP. Neighborhood sociodemographic and environmental contexts and self-rated health among Brazilian adults: a multilevel study. Cad Saude Publica 2010; 26(12):2368-2378.

11. Gift HC, Achison KA. Oral health, health, and health-related quality of life. Med Care 1995; 33(Supl. 11):57-77.

12. Walter MH, Woronuk JI, Tan H, Lenz U, Koch R, Boening KW, Pinchbeck YJ. Oral health related quality of life and its association with sociodemographic and clinical findings in 3 northern outreach clinics. J Can Dent Assoc 2007; 73(2):153.

13. Pattussi MP, Peres KG, Boing AF, Peres MA, Costa JS. Self-rated oral health and associated factors in Brazilian elders. Community Dent Oral Epidemiol 2010; 38(4):348-359.

14. Cohen-Carneiro F, Souza-Santos R, Rebelo MA. Quality of life related to oral health: contribution from social factors. Cien Saude Colet 2011; 16(Supl. 1):1007-1015.

15. Lamarca GA, Leal MC, Leão AT, Sheiham A, Vettor MV. Oral health related quality of life in pregnant and post partum women in two social network domains; predominantly home-based and work-based networks. Health Qua Life Outcomes 2012; 10:5.

16. Reisine ST. Theoretical considerations in formulating sociodental indicators. Soc Sci Med 1981; 15(6):745750 .

17. Atchison KA, Dolan TA. Development of the Geriatric Oral Health Assessment Index. J Dent Educ 1990; 54(11):680-687. 
18. Leão A, Sheiham A. Relation between clinical dental status and subjective impacts on daily living. J Dent Res 1995; 74(7):1408-1413.

19. Adulyanon S, Sheiham A. Oral impacts on daily performances. In: Slade GD, editors. Measuring Oral Health and Quality of Life. Chapel Hill: University of North Carolina; 1997. p.151-160.

20. Slade GD. Derivation and validation of a short-form oral health impact profile. Community Dent Oral Epidemiol 1997; 25(4):284-290.

21. Fernandes MJ, Ruta DA, Ogden GR, Pitts NB, Ogston AS. Assessing oral health-related quality of life in general dental practice in Scotland: validation of the OHIP14. Community Dent Oral Epidemiol 2006; 34(1):53-62.

22. Rener-Sitar K, Petricević N, Celebić A, Marion L. Psychometric properties of Croatian and Slovenian short form of Oral Health Impact Profile questionnaires. Croat Med J 2008; 49(4):536-544.

23. Montero-Martín J, Bravo-Pérez M, Albaladejo-Martínez A, Hernández-Martín LA, Rosel-Gallardo EM. Validation the Oral Health Impact Profile (OHIP-14sp) for adults in Spain. Med Oral Patol Oral Cir Bucal 2009; 14(1):E44-50.

24. Ferreira CA, Loureiro CA, Araújo VE. Psycometrics properties of subjective indicator in children. Rev Saude Publica 2004; 38(3):445-452.

25. Ikebe K, Watkins CA, Ettinger RL, Sajima H, Nokubi T. Application of short-form oral health impact profile on elderly Japanese. Gerodontology 2004; 21(3):167-176.

26. Lahti S, Suominen-Taipale L, Hausen H. Oral health impacts among adults in Finland: competing effects of age, number of teeth, and removable dentures. Eur J Oral Sci 2008; 116(3):260-266.

27. Guzeldemir E, Toygar HU, Tasdelen B, Torun D. Oral health-related quality of life and periodontal health status in patients undergoing hemodialysis. J Am Dent Assoc 2009; 140(10):1283-1293.

28. Bernabé E, Marcenes W. Periodontal disease and quality of life in British adults. J Clin Periodontol 2010; 37(11):968-972.

29. Bandéca MC, Nadalin MR, Calixto LR, Saad JR, da Silva SR. Correlation between oral health perception and clinical factors in a Brazilian community. Community Dent Health 2011; 28(1):64-68.

30. Mulligan R, Seirawan H, Alves ME, Navazesh M, Phelan JA, Greenspan D, Greenspan JS, Mack WJ. Oral health-related quality of life among HIV-infected and at-risk women. Community Dent Oral Epidemiol 2008; 36(6):549-557.

31. Locker D, Quiñonez C. To what extent do oral disorders compromise the quality of life? Community Dent Oral Epidemiol 2011; 39(1):3-11.

32. Mesquita FAB, Vieira S. Self evaluated oral status impact on quality of life. RGO 2009; 57(4):401-406

33. Almeida AA, Loureiro CA, Araújo VE. Um estudo transcultural de valores de saúde bucal utilizando o instrumento OHIP-14 (Oral Health Impact Profile) na forma simplificada. Parte I: adaptação cultural e linguística. UFES Rev Odontol 2004; 6(1):6-15.
34. Oliveira BH, Nadanovsky P. Psychometric properties of the Brazilian version of the Oral Health Impact Profileshort form. Community Dent Oral Epidemiol 2005; 33(4):307-314

35. Locker D. Measuring oral health: a conceptual framework. Community Dent Health 1988; 5(1):3-18.

36. Slade GD, Spencer AJ, Locker D, Hunt RJ, Strauss RP, Beck JD. Variations in the social impact of oral conditions among older adults in South Australia, Ontario, and North Carolina. J Dent Res 1996; 75(7):1439-1450.

37. Slade GD, Nuttal N, Sanders AE, Steele JG, Allen PF, Lahti S. Impacts of oral disorders in the United Kingdom and Australia. Br Dent J 2005; 198(8):489-493.

38. Fleck MPA, Louzada S, Xavier M, Chachamovich E, Vieira G, Santos L, Pinzon V. Application of the Portuguese version of the abbreviated instrument of quality life WHOQOL-bref. Rev Saude Publica 2000; 34(2):178-183.

39. Sherbourne CD, Stewart AL. The MOS social support survey. Soc Sci Med 1991; 32(6):705-714.

40. World Health Organization (WHO). International guide for monitoring alcohol consumption and related harm. Geneva: WHO; 2000.

41. Courtenay WH. Constructions of masculinity and their influence on men's well-being: a theory of gender and health. Soc Sci Med 2000; 50(10):1385-1401.

42. Pinheiro RS, Viacava F, Travassos C, Brito AS. Gender, morbidity, access and utilization of health services in Brazil. Cien Saude Colet 2002; 7(4):687-707.

43. Finlayson TL, Williams DR, Siefert K, Jackson JS, Nowjack-Raymer R. Oral health disparities and psychosocial correlates of self-rated oral health in the National Survey of American Life. Am J Public Health 2010; 100(Supl. 1):246-255

44. Sanders AE, Slade GD, John MT, Steele JG, Suominen-Taipale AL, Lahti S, Nuttall NM, Allen PF. A cross-national comparison of income gradients in oral health quality of life in four welfare states: application of the Korpi and Palme typology. J Epidemiol Community Health 2009; 63(7):569-574.

45. Turrel G, Sanders A, Slade GD, Spencer AJ, Marcenes W. The independent contribution of neighborhood disadvantage and individual-level socioeconomic position to self-reported oral health: a multilevel analysis. Community Dent Oral Epidemiol 2007; 35(3):195-206.

46. Locker D. Concepts of oral health, disease and the quality of life. In: Slade GD, editor. Measuring oral health and quality of life. Chapel Hill: University of North Carolina; 1997. p. 12.

47. Allison PJ, Locker D, Feine JS. Quality of life: a dynamic construct. Soc Sci Med 1997; 45(2):221-230.

48. Berkman LF, Glass T, Brissette I, Seeman TE. From social integration to health: Durkheim in the new millennium. Soc Sci Med 2000; 51(6):843-857.

49. Aldabe B, Anderson R, Lyly-Yrjänäinen M, Parent-Thirion A, Vermeylen G, Kelleher CC, Niedhammer I. Contribution of material, occupational, and psychosocial factors in the explanation of social inequalities in health in 28 countries in Europe. J Epidemiol Community Health 2011; 65(12):1123-1231. 
50. Taylor SE, Seeman TE. Psychosocial resources and the SES-health relationship. Ann NY Acad Sci 1999; 896:210-225.

51. Krieger N. Theories for social epidemiology in the 21st century: an ecosocial perspective. Int J Epidemiol 2001; 30(4):668-677.

52. Paula JC, Leite ICG, Almeida AB, Ambrosano GMB, Pereira AC, Mialhe FL. The influence of oral health conditions, socioeconomic status and home environment factors on schoolchildren's self-perception of quality of life. Health Qual Life Outcomes 2012; 10:6.

53. Stahlnacke K, Soderfeldt B, Unell L, Halling A, Axtelius B. Perceived oral health: changes over 5 years in one Swedish age-cohort. Community Dent Oral Epidemiol 2003; 31(4):292-299.

Article submitted 27/07/2014

Approved 14/09/2014

Final version submitted 16/09/2014 